\title{
Aging with Creativity
}

\author{
Irene L Nielsen* \\ Historical Echoes, Ashford University, USA \\ Submission: March 23, 2018; Published: September 18, 2018 \\ *Corresponding author: Irene L Nielsen, Historical Echoes, Ashford University, USA, Email: irenesteas@gmail.com
}

\section{Abstract}

Renewed interest in creativity and novel thinking has recently been acknowledged to understand challenges of an increasingly complex world. Much of the interest has ignored the important aspects of aging with creativity. Brain pathways for divergent thinking are established well into old age. Neuroscience and imaging technologies show two separate, higher order, creative pathways from the hippocampus of memory and from the amygdala in the limbic system. The Temporal-Occipital-Parietal (TOP) cortical juncture manages the thoughts and memories rationally or with emotion. Pathways require fluidity, openness, and flexibility to engage in novel, uninhibited, thinking. Artistic and scientific creative thinking are similar but different. Basic knowledge of the domain, acquired by experience, is essential for divergent thoughts and creative products.

Personality attributes from genetic and environmental experiences may be markers for development of resiliency and an ability to take risks for novel problem solving. An optimistic, creative, older person who develops wisdom from experience and indulges in solitary, reflective thinking is an asset to creative problem solving efforts. Erikson's stages of successful life development empower older adults for thoughtful, novel risks with mental flexibility while open to new ideas without fear of social disapproval. Creativity is far from being bound by chronological aging, but limitations are often culturally imposed with self-fulfilling indicators of declinism that linger from inaccurate studies and academic reports from the 1950s. Advances in plastic neurology open understanding for creativity in old age. Creativity from experiences and wisdom may be a significant asset of the greying U.S. population.

Keywords: Aging; Creativity; Personality; Brain; Declinism; Ageism; Old age

Abbreviations: TOP: Temporal-Occipital-Parietal; DLPFC: Dorsal Lateral Pre-Frontal Cortex; VMPFC: Ventromedial Prefrontal Cortex; OCEAN: Openness, Conscientiousness, Extraversion, Agreeableness, and Neuroticism; APOE: Apolipoprotein E

\section{Introduction}

Creativity, or the mysticism of special talents and abilities, has been a fascinating subject for most of human history. It has morphed from spiritual powers exhibited by shamans to accusations of witches. In the 20th century it was linked with giftedness, personality, and sometimes, psychosis.

Assertions cycle that novel thoughts for problem solving remains a positive evolutionary force that advance civilization and relationships. Research continues to link artistic creativity with hypomania and schizophrenia or scientific creativity to depression and bipolar characteristics [1].

Renewed interests in understanding positive uses for creativity were born of industrial progress in the 1950s. Brain imaging technology and understanding improved as interests increased in the neurobiology and psychology fields. Challenges to traditional education opened efforts to promote environments suitable to fostering calculated risk taking, openness to new ideas, and development of trust and security to those with creative mindsets.

The late 20th century focused on team building and collaboration, but such efforts are the antithesis of developing creativity.
The creative mind works best in isolation where one's focus can tolerate self-reflection and make self-corrections. Brain storming works for team building but not for fostering new and unique solutions suitable for novel problems solving.

The focus of creativity on child development and organizational development is laudable, but this paper will build from those foundations to explore neuronal, personality, and social basics of creativity in old age. Creativity and relevancy remain important to maintaining mental and physical health in old age. The old person who contributes is less likely to feel redundant.

Each life stage faces unique health and diseases. Childhood and adolescents have their professional specialists. Old age has been largely ignored as inevitable and untreatable. Aging is no more a disease than is adolescence or childhood, yet like childhood, certain disease are known to be threats to the lifestage. Declinism with ageism focuses excessively on the pathophysiology of physical strengths and fears of the adult brain. Novel thought and openness stimulate increased development of neurons throughout life [2]. Mental flexibility, openness, and risk-taking for new and novel experiences are cornerstones of creativity. 
Declinism, as promoted by the industry of physical perfection and the youth culture, views aging as a predictable, downward tract into irrelevancy and inefficacy. The ideology of the human as a machine fails to consider the diversity, resiliency, and wisdom of the human body and mind [2-5].

\section{Creativity and Neuroscience}

It is important to examine the basic neurological functions of the brain. Most studies on creativity explore the functionality of thought, leaving the definition of creativity as a useful end-product unclear. The most consistent definition of creativity is novel, divergent thinking or problem solving that implores mental openness and flexibility.

The pre-frontal cortex is highly specialized to higher cognitive functions. One pathway projects embryologic tissue from the hippocampus to the frontal lobe for consciousness, memory and decision making. The dorsal lateral pre-frontal cortex (DLPFC) area locates the scientific, step-wise creative pathway. Working memory is limited and able to attend to only about four concepts in serial order. Focused attentiveness is necessary for disciplined openness leading to novel thinking [6].

Artistic and emotional creativity follows the parallel, but independent pathway, apart from scientific creativity. The amygdala neurons of the limbic system project to affective higher orders areas "by the cingulate cortex and ventromedial prefrontal cortex" (VMPFC) [6]. Both pathways project into the cortex for integration at the juncture of the temporal, occipital, parietal area (TOP). The neurons here are devoted to sensory integration and long-term memory [6].

In either pathway, a buffer system that allows for long-term sustained working memory is necessary for "cognitive flexibility, abstract thinking, strategic planning access to long-term memory and sentience" [6]. Older persons who endorse the myth of inevitable declinism are most likely to develop crystallized thinking and believe in the disease of aging. Reinforced neurological pathways of predictable, inflexible thinking are the anathema to creativity. Mental flexibility and openness remain essential for creativity and brain plasticity.

To build new neurons and to keep the brain vibrant, older adults must maintain openness with curiosity and wonderment. The abilities to wonder, to play, and to imagine are foundations for new neuro stimulation, neuronal growth, and creative thought [2]. The ability to suspend conscious inhibitions allows for imaginative play and free, creative thoughts that then the individual must evaluate before the work of pruning and commitment of an idea or thought can begin [7].

Intuition is the free-thinking to arrive at a decision point without reasoning. Intuition is a starting point - not an end point of creativity. Deliberations can involve both pathways for rational and emotional openness. Retrieval of thoughts and memories is associated with personal resilience and consistent with one's cultural and belief systems [6]. Experiences of coping with adversity facilitates a development of resiliency, but also contrib- utes to reinforcement for openness, optimism, and self-efficacy [8].

Knowledge in a domain increases divergent thinking applicable to the creative thought in the domain. Experiences with reflection and flexibility are measures of operational wisdom that reinforce openness and flexibility that develop in novel thinking. Nimbleness and integration with emotion in the pre-frontal cortex separates stark, inhibited repetition from novel thinking.

Creativity not only involves novel thinking but also cultural and social appropriateness. The pre-frontal cortex is the last area of the brain to mature and mylenate around the mid-20s for a young adult [9]. Young people, by definition, have a limited amount of stored memories and experiences that are accessible to divergent thinking in the TOP. New information shows an increasing number of persons over 60 who are becoming entrepreneurs, are redefining work, and through experience have an edge over younger persons. The over 60 population is the fastest growing and largest group of new American businesses [10,11].

Older adults who are able to reflect and seek the thrills and risks of novelty with divergent thinking, add wisdom to their openness. Such persons enhance both growth of neurons through life but add to their abilities for divergent problem solving and a life satisfaction. A personality that seeks efficacy and resiliency from life adversities may be uniquely prepared to contribute to family and communal challenges through assets of both wisdom and creativity. The stereotypical, cultural paradigm of ageism undermines the unique hearing of the creative possibilities available only to older adults with emotional and mental flexibility.

A lifetime of coping with adversity and development of resiliency increases the individual self-esteem, optimism, and personal control [8]. With self-efficacy and optimism, adversities become assets increasing the positive world-view and satisfaction of personal control. Adverse experiences, viewed in retrospect, are stories to be told - often with the perspective of creative humor [8].

\section{Personality}

Research on the creative personality was most aggressively pursued after the 1950s. Intelligence is often mixed as a variable with personality, but the consensus is that higher intelligences are usually a part of creative, divergent thinking [12]. References to psychometrics of creativity and personality have re-surfaced in current literature.

Batey \& Furnham [12] noted that when highly creative, artistic individuals are compared to less creative persons, within-the-group differences are significant. Creative persons may be labeled by a hierarchy as difficult or sometimes, aloof. More creative persons are less "deferent and team oriented; more aggressive, dominant, and autonomous; and [are] less socialized" (p 383). Independence appears important. Lower measures of agreeableness on the Big Five personality assessment indicate "less concern for convention or conscientiousness" [12]. 
The Big Five Personality test has most frequently been used as a standard assessment for Openness, Conscientiousness, Extraversion, Agreeableness, and Neuroticism (OCEAN) [13]. Because of its frequent use in studies, it is a most meaningful communication tool for characteristics.

Openness (0) to novel and new ideas or experiences is a constant characteristic for creativity both in artistic and scientific measures. It "emerged as the strongest and most consistent predictor" of creativity [13].

Conscientiousness (C) is a characteristic of creativity in the scientific domain, but not necessarily in the artistic one. Both positive and negative factors depend on the internal or external locus of control with components of achievement and dependability. Achievement is positively related when it is self-oriented. Dependability is negatively oriented when it becomes other-dependent with an external locus of control [13].

Batey \& Furnham [12] report extraversion (E) as non-typical both in artistic and scientific creative profiles. This conclusion differs from works reported by Christensen et al. [13] who found extraversion to be a good predictor of creativity in divergent thinking.

Agreeableness (A) has relatively little effect on creativity [13]. Agreeableness with an internal control is reflective of the characteristics described as autonomous and less concern for social convention or external approval [14].

Higher levels of neuroticism (N) appear characteristic of artistic creativity, but are voided in scientific creativity. It may the rumination to keep trying to redo the thought and outcomes that leads an artistically creative personality. Neuroticism can also be linked with negativity and in excess may approach mental dysfunction [1]. The Myers Brigg assessment is sometimes used to understand personalities of creative thinkers. The Thinking and Feeling dichotomies reveal both emotional and cognitive styles of a self. The broadly inclusive, divergent thinking personality lives comfortably in the feeling, intuition and perceiving worlds of the self [15].

The creative personality is often viewed as a societal misfit who challenges and agitates for new, divergent, and novel explorations from a static culture of the comfortable masses. Picasso is reported to have said, 'Art is a lie that reveals truth' [1]. Perhaps creativity is open to challenge both truths and lies found within a culture. Creativity is not par with psychosis, but perhaps there is a link separated by an awareness of reality $[1,16,17]$.

\section{Social Integration, Life Satisfaction, and Aging}

\section{Social Integration}

It is evident that various aspects of personal expression, including divergent and novel thinking are more or less acceptable to social relationships. A creative individual who prefers to think alone will be viewed differently than one who is an exhibitionist who enjoys publicly sharing ideas and divergent works. Either situation must remain flexible, internally or externally to work creatively. The extrovert who uses the audience to hone the craft may not approach social intimacy or team-building that is currently so acceptable to a structured hierarchy.

The creative extrovert agonizes and recoils over present social movements pushing for team-building and collaboration. Brain-storming, focused on group-think of quantity, disgusts the creative individual who best works alone, and who often reveals work after isolated periods of reflection with multiple self-corrections.

Creativity is sensitive to a myriad of social and personal issues, but it generally avoids convergent thinking and negative victimizations. Fluidity and flexibility with playfulness and humor opens and lightens the interactive neuro pathways to inclusive thought and imagination.

Positive family emotional relationships encourage and support creative risk-taking. Environmental security with trust and freedom from discrimination underscores opportunities for curiosity and fluid thinking. Self-efficacy, esteem, and optimism develop in creative expressions and resiliency [18]. Permission for fluid thinking is more often given to young persons, but when older adults explore both fluid and flexible thinking, society often finds it counter intuitive and seeks an allopathic categorization and pharmaceutical treatment.

Personality plays a part in the quantity of friendships at any age. Friends are often a reflection of one's own interests and curiosities. In older ages, the numbers of relationships become less important than the quality of them. Creative and intelligent older persons define the circle of trusted relationships according to their own unique need and comfort zones of divergent thinking.

The social question of creativity influenced by gender roles was addressed by Norlander, et al. [19]. The recent emancipation of women raises the question of current gender roles as evidenced in creative outputs. The researchers found men and women who embraced androgyny were most highly creative. Individuals who were most gender stereotypical were most optimistic but were significantly less creative. The assumption is made that stereotypical optimism reflects a comfortable, social endorsement and therefore a decrease in stress.

Perhaps social comfort increases inertia and decreases a desire or need for flexible thinking. Savishinsky [20] revealed movements for retirees to learn to just be are at a cross roads when elders wish to do. Thomas pushes for older persons to be as essential to grand-parenting, but not all older person is or wish to be grandparents in the traditional understanding.

Retirees and older persons often express a renewed freedom of both being and doing. Creativity is the voyage for the next passage of expression and meaning. For some older adults, the passion for expressing creativity has been on hold for the years during socially acceptable work and family responsibilities. The introspective, creative exercise of maturity is a critical process of evolving with meaning while selectively disengaging for previ- 
ous roles. There is "an ageless sense of self even as their bodies, their minds and their social roles alter with time" [20].

Sorman et al. [21] reviewed literature seeking correlations between physical and social activity and dementia for older adults. Popular literature generally promotes a simplistic prescription and an obsession for these activities as preventions of dementia. The authors carefully selected out of their study any persons with early dementia indicators and any subjects who were carriers of the apolipoprotein E (APOE) genetic factor associated with dementia, notably Alzheimer's disease.

It is significant to note that the authors indicate the genetic APOE selection was an unusual step not often noted in studying correlations of dementia with physical and social activity [21]. Their study indicated that for healthy persons over the 15 years of their study there was no significant long-term correlation between physical or social activity and dementia. Apparently, the promoters of declinism in old age will have to reassess simplistic views of physical and social categories as remedies for dementia. Healthy novel and creative thinking remain an individualistic activity, shared at will after self-reflection processes.

\section{Life satisfaction}

Gerontologist, Gene Cohen asserts that in old age, creativity takes on risks and controversies with courage [7]. Erikson's eighth stage of human development posits the shift is from an ego-centric development of youth to the generativity of multi-generational inclusiveness. Successful mastery of previous developmental stages releases generativity versus the despair of unsuccessful stages of life development [22]. Creative, divergent thought, and a new way of being can expose novel divergence as required for internal control, optimism and self-efficacy. A transformational milestone, reached in old age, may open creative imagination and free one of risks from social disapproval that no longer matter.

\section{Aging}

Creativity in later life can encourage individual freedoms for the open, flexible thinker. In old age being alone is not loneliness when engaged with imaginative, satisfactory, novel thinking. The pleasure of one's own company is a gift. Schmidt [23] asserts the necessary joy and productive satisfaction that a visual artist needs for solitary work at any age. An older person with novel thinking often develops self-control that allows a major rejection of 21 st century activities of group work and brain-storming.

"Creative thinkers sustain high standards of work ethic[s]... work[ing tirelessly] until the opus is completed. Older people who are creative report that their productivity is high, with little focus on physical complaints" [23]. Optimism and efficacy in older ages contribute significantly to personal well-being when engaged with creative focus. Individualism is a gift for a life-style of creativity. Individualism in the Western tradition promotes satisfied achievements such as discussed by Jung and disseminated by Maslow. "The vital, lifelong process of personal [resiliency] growth and reevaluation" leads to self-actualization. It measures divergent, creative contributions that are tentative in childhood and are liberated from experience in old age.

Beginning from 1995, the National Endowment for the Humanities and Administration on Aging promoted artistic expressions to foster an elevated quality of life for older Americans. Policies and funding have been slow to respond, though community and long-term care facilities have individually demonstrated increased well-being and independence, decreased pain, and more life satisfaction for older persons with access to artistic expressions. The aging Baby Boomers now demand more creative living than their parents who settled for Bingo-night [24].

The creative limitations of the future are reflected from the echoes of the past. People, families, organizations, and societies are conditioned through rigid, inaccurate, research from academics who seek truth through replication of old paradigms. Shearring [25] exposes the myths of ageism that continue to plague society and economics.

Self-fulfilling prophesies perpetuate prejudices against important creative contributions of older adults. Studies cited from the 1950s through the 1990 s slowly began to question the accuracy of biologically ordained declinism. In the period before neuroplasticity was understood, academics declared the human brain function automatically declined as an industrial motor would wear out in time [5]. The psychological academics and society believed what they were told - that old people automatically become redundant and unnecessary drain on society. These mistakes and the prejudices that old people cannot learn new skills continue to be wrong and destructive to society.

It has been further taught that creativity is an activity for the young. While many unique, scientific breakthroughs are by scientists in the first career decade, the accumulation of experience and wisdom in their domain allows significant creative expressions following years of developing divergent thinking habits $[2,23]$.

A 1990 study showed there was no difference in a word processing mastery classes between a group of participants 18 - 30 years of chronological age and those 65-75 years of chronological age [25]. Additionally, a longitudinal study reported by Andersson et al. reported fluency, flexibility, and originality of participants between 1971 and 1972 and re-tested in 1984 was unchanged by 13 years of aging.

Competency and creativity have not been shown to be affected by chronological age Schmidt [23]. Certain personality characteristics of resiliency are more weighted toward novel and divergent problem solving. Awareness of the creative person in old age can only be accentuated now by the increases in the greying population. Living, or aging, through external social control and matters of agreeableness dictated by other's expectations deprives all of us of accumulated, creative wisdom that our society desperately needs to mature. 


\section{Conclusion}

Creativity as a flexible, fluid, mental activity is largely an individualistic exercise engaged in relative isolation with playfulness, incubation, and self-corrections. Conclusions of the individual, creative mind might later become the work of larger groups and specific disciplines who later endorse the novel thinking. Creativity is probably a matter of personality, reinforced by a safe, nurturing environment of safe risk-taking and curiosity. Moderately high levels of intelligence are presumed, and the appreciated age-related experiences of wisdom development contribute positively to society as a whole.

Prejudices against creative contributions of old people are largely matters of believing the outdated, inaccurate research and academic reports from the 1950s. Self-efficacy, resiliency, and self-esteem are characteristics available to all ages but mature through resiliency developed by experiences. Openness, optimism, self-esteem, and flexibility are creative assets of choice and environmental conditioning. These creative assets are not limited by a specific calendar age, but wisdom through aging enhances the divergent possibilities.

\section{References}

1. Thys E, Sabbie B, De Hert M (2013) Creativity and psychiatric illness: The search for a missing ling -An historical context for current research. Psychopathology 46: 136-144.

2. Heilman KM (2005) Creativity and the brain. NY, NY: Psychology Press Taylor \& Francis Group, pp. 224.

3. Sternberg RJ (2001) What is the common thread of creativity?: Its dialectical relation to intelligence and wisdom. American Psychologist 56(4): 360-362.

4. Takahashi M, Overton WF (2005) A handbook of wisdom: Psychological perspectives. Sternberg RJ, Jordan J (Eds.) NY, NY: Cambridge University Press.

5. Thomas WH (2004) What are old people for?: How elders will save the world. Acton, MA: Vander Wyk \& Burnham.

6. Dietrich A (2004) The cognitive neuroscience of creativity Psychometric Bulletin \& Review 11(6): 1011-1026.

7. Cohen GD (2000) The creative age: Awakening human potential in the second half of life. NY, NY: Harper Collins.

8. Nielsen IL (2014) Relationship of Adversity and Resiliency on Subjective Well-Being in Women Born Between 1930 and 1940 (Doctoral dissertation, University of the Rockies, 2014). Dissertation Abstracts.
9. Sapolsky R (2005) Biology and human behavior: The neurological origins of individuality [DVD] (1597). Chantilly, VA: The Teaching Company.

10. Dickson D (2012) Over 60 entrepreneurships is redefining work. Aging Today 33(2): 11.

11. Freedman M (2012) Why older entrepreneurs have an edge. Aging Today xxxiii(6): 11.

12. Batey M, Furnham A (2006) Creativity, Intelligence, and Personality: A critical review of the scattered literature. Genet Soc Gen Psychol Monogr 132 (4): 355-429.

13. Christensen BT, Drewsen LK, Maaloe J (2014) Implicit theories of the personality of the ideal creative employee. Psychology of Aesthetics, Creativity, and the Arts 8(2): 189-197.

14. DeYoung CG, Hirsh JB, Shane MS, Papademetris X, Rajeevan N, et al. (2010) Testing predictions from personality neuroscience: Brain structure and the big five. Psychol Sci 21(6): 820-828.

15. Quenk NL (2009) Essentials of Myers-Briggs type indicator assessment ( $2^{\text {nd }}$ edn.) Kaufman AS, Kaufman NL (Eds.). Hoboken, NJ: John Wiley \& Sons.

16. Flaherty A (2011) Brain illness and creativity: Mechanisms and treatment risks. Canadian Journal of Psychiatry 56(3): 132-143.

17. Lauronen E, Vejola J, Isohanni I, Jones P, Nieminen P, et al. (2004) Links between creativity and mental disorders. Psychiatry 67(1): 81-98.

18. Bagherpour T, Jahanian R (2012) The psychology of creativity growth and strategies. International Journal of Academic Research in Business and Social Sciences 2(4): 344-349.

19. Norlander T, Erixon A, Archer T (2000) Psychological androgyny and creativity: Dynamics of gender-role and personality trait. Social Behavior and Personality 28(5): 423-435.

20. Savishinsky J (2001) The passion of maturity: Morality and creativity in later life. Journal of Cross-Cultural Gerontology 16(1): 41-55.

21. Sorman DE, Sundstrom A, Ronnlund M, Adolfsson R, Nilsson LG, et al. (2014) Leisure activity in old age and risk of dementia: A 15-year prospective study. J Gerontol B Psychol Sci Soc Sci 69(4):493-501.

22. Dunkel CS, Sefcek JA (2009) Eriksonian lifespan theory and life history theory: An integration using the example of identity formation. Review of General Psychology 13(1): 13-23.

23. Schmidt PB (2006) Creativity and coping in later life. Generations 30(1): 27-31.

24. Hanna G (2006) Focus on creativity and aging in the United States. Generations 30(1): 47-49.

25. Shearring HA (1992) Creativity and older adults. Leadership \& Organization Development Journal 13(2): 11-16. 
Your next submission with Juniper Publishers will reach you the below assets

- Quality Editorial service

- Swift Peer Review

- Reprints availability

- E-prints Service

- Manuscript Podcast for convenient understanding

- Global attainment for your research

- Manuscript accessibility in different formats

( Pdf, E-pub, Full Text, Audio)

- Unceasing customer service

Track the below URL for one-step submission https://juniperpublishers.com/online-submission.php 